\title{
Traduçáo de poesia entre português e chinês: pesquisa e catalogação historiográfica na Universidade de Macau
}

Raquel Abi-Sâmara

Márcia Schmaltr.

\begin{abstract}
Resumo: O presente artigo apresenta o projeto de pesquisa "Historiographic Research on Translation of Poetry Between Portuguese and Chinese" conduzida pelas autoras. Destaca-se a fundamentação teórica da pesquisa, com bases nas oito perguntas de D’hulst (2001) para uma escrita historiográfica. Uma tabela ilustrativa é apresentada como o primeiro resultado prático de uma catalogação bibliográfica de livros de poesia chinesa traduzidos para o português, e vice-versa, que será em breve disponibilizada na página eletrônica da Universidade Macau.
\end{abstract}

Palavras-chave: historiografia da tradução, tradução literária, poesia, chinês-português

\section{Introdução}

O lugar estratégico e incontroverso que Macau ocupa na história das relações entre a língua chinesa e a língua portuguesa justifica iniciativas de pesquisas de caráter historiográfico na área dos estudos da tradução do par linguístico português-chinês, realizadas sobretudo nos últimos 15 anos em Macau1. Para o estudioso da tradução literária, no entanto, ainda não há uma catalogação sistematizada das obras traduzidas do chinês ao português, e vice-versa, que ofereça opções de buscas seja por títulos das obras (original e/ou traduzida), seja por autor, por tradutor, por editora, ano de edição, entre outras informação por meio

1 Uma primeira compilação de obras e autores portugueses traduzidos em línguas orientais até 1999 foi organizada pelo Instituto Oriente (2000), como explicaremos mais adiante. 
eletrônico. A constatação dessa lacuna e o propósito de oferecer uma ferramenta de apoio dessa natureza levou-nos a iniciar a pesquisa "Historiographic Research on Translation of Poetry Between Portuguese and Chinese" na Universidade de Macau (UM), projeto que envolve docentes e estudantes de graduação e de pós-graduação em Estudos da Tradução dessa instituição. Nosso objetivo aqui é apresentar esse projeto, iniciado em agosto de 2012, e seu primeiro resultado, que consiste em um catálogo bibliográfico online voltado exclusivamente, neste primeiro momento, para o registro de traduções (e tradutores) de poesia.

Para iniciar esta apresentação, sintetizaremos as justificativas e fundamentações teóricas de nossa pesquisa, com bases no historiographic turn ocorrido nos Estudos da Tradução (MILTON; MARTINS, 2010) e pautadas nas oito perguntas propostas por Lieven D’hulst (2001) para a escrita de histórias da tradução. Em seguida, destacaremos publicações historiográficas relevantes que nos serviram como ponto de partida para essa pesquisa. $\mathrm{Na}$ sequência, mostraremos o atual estágio da pesquisa e objetivos a serem cumpridos. Por fim, vamos discutir brevemente a primeira pergunta proposta por D'hulst ao pesquisador historiográfico da tradução: Quis, ou seja, "quem" é o tradutor de poesia nas obras traduzidas do chinês ao português e, vice-versa, do português ao chinês? A expressão "tradutor(a) de poesia" ou mesmo "tradução de poesia" será suficiente para acolher entendimentos e abordagens tão distintas dos agentes desse "transportar" (übersetžen) de um poema de um idioma para outro tão distante linguisticamente?

\section{Fundamentação teórica}

Os Estudos da Tradução vêm investindo, principalmente na última década, na construção de uma história da tradução, fundamental para ampliar os conhecimentos do estudioso e do tradutor, e para fornecer-lhes um panorama das perspectivas teóricas e dos pontos de vistas dos tradutores ao longo dos tempos. John Milton e Márcia Martins acreditam em “uma 'virada historiográfica' nos Estudos da Tradução nos moldes da 'virada cultural' dos anos 1990 e da 'virada política' que veio algum tempo depois" (2010, p. 9-10). Para reforçar seu argumento, os autores referem-se às palavras de Kuhiwczac e Littau, em Companion to Translation Studies: "agora a disciplina busca um novo conhecimento de si mesma voltando-se para a história: seja a sua história como disciplina, a história das teorias da tradução, o papel que a tradução desempenhou na história do livro ou da indústria editorial, ou uma história sociocultural dos tradutores" (2007, p. 5).

Com relação à história da tradução literária do par chinês-português nos países de expressão portuguesa e também na China, há ainda pouco material 
publicado. Nesse sentido, vale destacar aqui os trabalhos historiográficos de Yao (2001) e de Teng (2011). São aparentemente poucos os romancistas e poetas de língua portuguesa com livros traduzidos para o chinês. Se estivermos falando de autores contemporâneos, torna-se radicalmente enxuta a lista de publicações (cf. a Apresentação deste Especial). E, ainda, se restringirmos nossa busca à literatura de expressão portuguesa escrita no Brasil, talvez cheguemos a uma dúzia de autores, com destaque para Jorge Amado, Paulo Coelho e Augusto Curi (que recentemente teve sua obra premiada na China). Se pensarmos em termos de obras de escritores brasileiros e portugueses sendo traduzidas atualmente para o chinês, talvez possamos apontar somente cinco, de que temos notícia no momento: Ensaio sobre a lucider, de José Saramago, Alberto Caieiro de Fernando Pessoa (outros dois títulos são traduções indiretas do inglês) e $O$ filho eterno, de Cristóvão Tezza. Muito provavelmente, o número de obras chinesas sendo traduzidas no Brasil no momento seja maior do que o de obras brasileiras traduzidas na China, em função do recente Prêmio Nobel da Literatura atribuído ao autor chinês Mo Yan. Mas, em termos estatísticos e numéricos, onde poderemos ter acesso a essas informações? O que já se traduziu, por exemplo, no Brasil ou em Moçambique, Cabo Verde, Portugal e outros países, de poesia chinesa contemporânea? E o que se traduziu de poesia lusófona contemporânea para o chinês?

O objetivo maior desta investigação historiográfica de tradução literária entre chinês e português é compilar uma base de dados que abranja prosa e poesia traduzidas, além de um dicionário de tradutores, nos moldes do DITRA, Dicionário Online de Tradutores da Universidade Federal de Santa Catarina ${ }^{2}$. No entanto, a primeira etapa da pesquisa teve como objeto a tradução de poesia do par linguístico chinês-português do último século, mais exatamente, livros publicados entre 1900 e 2013. A primeira versão do dicionário de tradutores incluirá somente tradutores de poesia, e não de prosas ficcionais, e terá sua primeira versão lançada na página eletrônica da UM ainda este ano, abrangendo tradutores que tenham publicado livros de poesia chinesa e/ou lusófona nos últimos 5 anos (2008-2013). O dicionário continuará sendo atualizado e ampliado após a divulgação de sua primeira versão.

\section{Metodologia}

Para a organização e revisão do material bibliográfico reunido, orientamo-nos a partir das oito seções básicas apresentadas por D’hulst (2001), com relação

2 Página eletrônica disponível em: < http://www.dicionariodetradutores.ufsc.br/pt/index.htm>. Acesso em 30 de abril de 2012 . 
à análise da produção das traduções: Quis (quem?), Quid (o que?), Ubi (onde?), Quibus auxilius (quem ajuda?), Cur (por que?), Quo Modo (de que maneira?), Cum (quando?), Cui Bono (para quem?). Seis dessas oito perguntas compõem os familiares "Seis Ws" para os jornalistas alemães, que consistem nas seis perguntas básicas que devem ser respondidas para a composição do primeiro parágrafo de uma notícia jornalística: Wer (quem), Was (o que), Wie (como), Wenn (quando), Warum (por que), Wo (onde). As duas perguntas aí acrescentadas por D'hulst (Quibus auxilius e Cui Bono) extrapolam o nível da escrita jornalística dos periódicos, que já têm definidos seu público-alvo (Cui Bono, para quem) e os eventuais patrocinadores (Quibus auxilius, quem ajuda), mas mostram-se fundamentais para a escrita histórica, não somente da tradução.

Entre outras questões suscitadas por essas e outras perguntas norteadoras do princípio historiográfico de D’hulst, podemos indagar: será que a poesia lusófona traduzida para o chinês dirige-se, por exemplo, a um público amplo, de nível escolar secundário ou superior na China? Ou estará direcionada para um público restrito e específico, o público leitor de poesia? Quem foram os tradutores? Exerciam outras profissões ou dependiam somente de tradução? Eram treinados para seu ofício de tradutor? Traduziam conforme certos conceitos ou poéticas? O que foi traduzido, na China e nos países de língua portuguesa, em termos de poesia portuguesa e chinesa? O que não foi traduzido? O que foi escrito sobre tradução de poesia do par chinês-português? O que se pode dizer acerca da distribuição geográfica de teorias sobre a tradução de poesia na China e em países de língua portuguesa? Quem foram os agentes das traduções, além do próprio tradutor? Por que foram traduzidos certos poetas e não outros? Como foram feitas as traduções? Considerou-se o aspecto sonoro nas traduções, ou apenas o aspecto semântico? Privilegiou-se o aspecto gráfico nas traduções? Por que determinados poetas e/ou poemas foram traduzidos na década de 1960 ou 1970, por exemplo? Qual o público-alvo das traduções dos poemas? Quando determinados poetas foram publicados, e por quê?

Naturalmente, a elaboração do nosso guia de consulta não está condicionada às respostas de muitas dessas perguntas. Mas outras vertentes de nossa pesquisa exigem essas reflexões, como o dicionário de tradutores do par chinês-português. Até o momento, tanto para o catálogo bibliográfico de poesia traduzida quanto para o dicionário de tradutores, uma das perguntas que mais têm nos exigido a atenção é a primeira pergunta de D'hulst (2001): Quis (quem)? Quem traduz? Mas, antes de abordarmos as dificuldades (ou as impossibilidades) de definição do termo genérico "tradutor(a) de poesia" para o par chinês-português, vamos citar a seguir estudos historiográficos que nos serviram como ponto de partida para a coleta de dados. 
A obtenção de informações estatísticas sobre a tradução chinesa e portuguesa tem se revelado árdua, recorremos a pesquisas nas bibliotecas nacionais do Brasil e de Portugal, Arquivo Histórico de Macau, o Index Translationum da UNES$\mathrm{CO}^{3}$ e do Sistema Integrado de Bibliotecas da China. Depois do cruzamento dos dados, ainda gostaríamos de saber sobre a situação da tradução de poesia chinesa contemporânea (e vice-versa) em Moçambique, Cabo Verde, Angola, Guiné-Bissau, São Tomé e Príncipe e Timor Leste.

\section{Revisão da literatura em historiografia da tradução poética}

Uma pesquisa de caráter historiográfico não poderia deixar de se fundamentar em estudos similares realizados na área de interesse dos analistas. A preocupação com a historicização das traduções poéticas do par chinês-português não é uma nova questão na Universidade de Macau. Um dos primeiros (senão o primeiro) estudos na área foi realizado por Yao Jingming, poeta, tradutor e professor do Departamento de Português da UM, em seu livro A poesia clássica chinesa: Uma leitura de traducões portuguesas (YAO, 2001). Em sua introdução, Yao apresenta um sucinto mas precioso histórico de publicações de poesia chinesa para o português, ao longo de 126 anos, desde 1870, quando surge talvez a primeira tradução de poesia chinesa em português, feita pelo escritor brasileiro Machado de Assis (18391908), tradução indireta realizada a partir da versão francesa de Judith Gautier, Le livre de jade, até as traduções dos poetas Li Bai e Du Fu feitas pela poetisa brasileira Cecília Meireles, em edição de 1996. Os primeiros poemas chineses vertidos para o português por tradutores portugueses, como destaca Yao, devem-se às traduções de António Feijó (Cancioneiro chinês, 1890) e de Camilo Pessanha (Oito elegias chinesas, 1894). Assim como Machado de Assis, Feijó fez suas traduções também indiretamente, a partir de Le livre de jade. A tradução de Camilo Pessanha, por sua vez, foi feita diretamente do chinês, com o apoio de amigos chineses, uma vez que o poeta/tradutor tinha ainda poucos conhecimentos do idioma chinês. Nossa pesquisa não deixa de ser uma ampliação dessa pesquisa histórica iniciada pelo colega Yao Jingming.

O catálogo Autores Portugueses em Linguas Orientais (2000), coordenado por Margarida Duarte, foi outra publicação em que também nos baseamos, e que informa sobre obras e autores portugueses traduzidos em línguas orientais. Dos 108 autores registrados, entre historiadores, filósofos, literatos entre outros, há

3 UNESCO. Index Translationum. Disponível em: <http://www.unesco.org/xtrans/bsresult.aspx? $\mathrm{lg}=0 \& \mathrm{sl}=$ zho\&l=por\&fr=50>. Acesso em 20 de maio de 2012 . 
15 poetas, mas apenas 6 deles com livros de poesia traduzidos para o chinês. Os outros restantes poetas, que escreveram também prosa, tiveram romances ou livros de contos traduzidos, mas não de poemas. Esse catálogo teve como suporte outro registro bibliográfico de autores e obras, conforme explicitado em sua introdução

Por iniciativa do Dr. Jorge Morbey, Diretor do Centro Cultural Português junto da Embaixada de Portugal em Pequim, foi elaborado um catálogo que reunia um registo bibliográfico de autores e obras de língua portuguesa, incluindo autores brasileiros, traduzidos em língua chinesa, que serviu de suporte a uma exposição bibliográfica aquando da visita do Presidente da República, Dr. Mário Soares, a Pequim, em 1995. É o primeiro embrião de catálogo de que temos notícia e dele colhemos a informação disponível. (IPOR, 2000, p. 15)

A presença chinesa no Brasil: pesquisa bibliográfica foi outro registro relevante para nosso trabalho. A pesquisa, que se encontra online, foi realizada por Lúcia Gaspar e Lúcia Cunha, bibliotecárias dos Institutos de Documentação e Tropicologia da Fundação Joaquim Nabuco, numa parceria da Fundação Joaquim Nabuco (Recife, PE) com o Instituto Internacional de Macau (2001). Das 163 referências bibliográficas levantadas por Gaspar e Cunha, nenhuma se refere diretamente às literaturas de língua portuguesa e/ou chinesa, mas foram indicações importantes de bibliografia para nossa pesquisa.

Outras duas publicações importantes, que nos serviram também de guia neste trabalho: Japanese Literature in Foreign Languages. 1945-1990, compilação de The Japan P.E.N. Club (1990) e Modern Japanese Literature in Translation. A Bibliography, coligido por The International House of Japan Library (1979). Embora as duas publicações não apresentem listagem completa dos títulos isolados dos poemas japoneses traduzidos para outras línguas estrangeiras, as poucas inserções de títulos isolados (e não somente dos títulos dos livros que contêm os poemas) revelam-se extremamente úteis em pesquisa específica sobre tradução de poesia. Após a divulgação de nosso catálogo, continuaremos trabalhando também nesse sentido, com a finalidade de especificarmos, sempre que possível, os títulos dos poemas traduzidos (títulos originais e títulos traduzidos), constantes dos livros de tradução catalogados.

Por fim, destacamos a pesquisa sobre a literatura latino-americana traduzida para o chinês realizada por Teng (2011). O autor apresenta uma importante fonte listagem de obras traduzidas entre 1949 e 1999, e trata também do contexto antecedente à proclamação da República Popular da China. Segundo o pesquisador, a escolha de obras a serem introduzidas na China nas primeiras décadas de 
1900 estava intrinsicamente relacionada à afinidade ideológica, particularmente às literaturas que versassem sobre a opressão e a libertação dos povos, além de oposição às grandes potências, num contexto de invasão estrangeira na China do século XIX. As palavras de ordem na altura eram Democracia e Ciência, seguindo o projeto de tradução de literatura estrangeira conduzido pelos irmãos Lu Xun e Zhou Zuoren (1909/1973) (SCHMALTZ; ZHANG, 2009 e ZHANG, 2009 e SCHMALTZ, neste volume), o Movimento da Nova Cultura. Em fevereiro de 1921, Mao Dun [茅盾], um dos expoentes do Movimento Quatro de Maio de 1919, publica "Um romance de um literato brasileiro" na revista Romance Mensal [小说月刊 Xiaoshuo yuekan], considerado o primeiro artigo introdutório da literatura latino-americana no Império do Meio. Mao Dun apresenta "Canãa (a partir da tradução inglesa) de Graça Aranha como a obra mais representativa de um dos maiores autores do Brasil" (SHEN, 1921, p. 4). Na resenha descreve o escritor como surrealista cuja narrativa versa sobre um jovem anarquista na luta pela construção da utopia no Brasil. Na "apresentação" do número 10 da mesma revista, Mao Dun, através de um panorama da literatura do Leste Europeu e da América do Sul, afirma que apesar das diferenças de código linguístico, das idiossincrasias na formação étnica, essas literaturas partilham o ponto comum de serem culturas oprimidas. Por outro lado, observa que cada sistema literário nacional apesar de compartilhar a mesma língua e viver sobre o mesmo contexto geográfico, histórico e cultural, é diferenciado, não se podendo portanto falar de uma literatura homogênea. $O$ intelectual exemplifica, com ênfase para a literatura de Graça Aranha, Coelho Netto, Afrânio Peixoto, Machado de Assis, de Queiroz, T., Lima, d'Almeida, F., Câmara, D.J., Lima, S.M. Artigos e estudos como estes nos oferecem pistas para podermos responder às perguntas de pesquisa e justificar a publicação da Antologia poética de Castro Alves em 1959, por exemplo.

\section{O catálogo}

Apresentaremos aqui um recorte mínimo da primeira versão de nosso catálogo. Embora composto por vários segmentos e seções, todos com pesquisas em andamento, serão divulgadas inicialmente apenas duas páginas, que contêm exclusivamente livros traduzidos (uma página referente à tradução do chinês ao português, e outra referente à tradução do português ao chinês). A coleta de poemas traduzidos e encontrados isoladamente em revistas de poesia, revistas acadêmicas, publicações online específicas de poesia, jornais e outros periódicos, têm demandado um trabalho minucioso de busca, e será lançado posteriormente, em 2014, em seção intitulada "Poemas em tradução" (uma página para a tradução de poemas 
publicados isoladamente - e não necessariamente em livros de poesia - do chinês ao português; outra para a tradução do português ao chinês), que abrangerá inicialmente o período de 1951 a 2013. Posteriormente nos concentraremos na seção de Prosa Traduzida, cujo acervo é consideravelmente maior do que o de poesia.

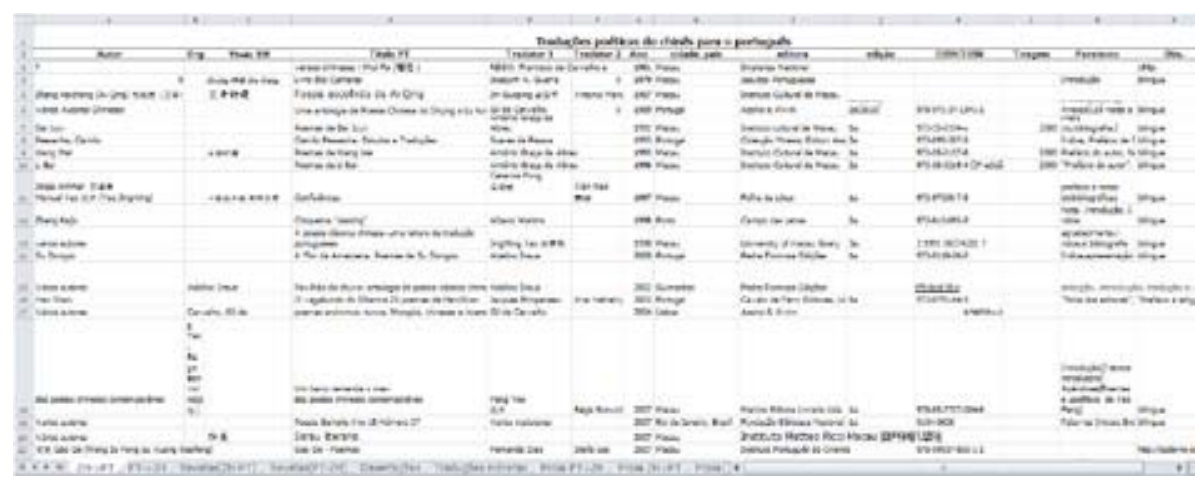

Tabela 1: printscreen da tabela referente à tradução poética do chinês para o português (Ver tamanho maior no Anexo I, p. 303).

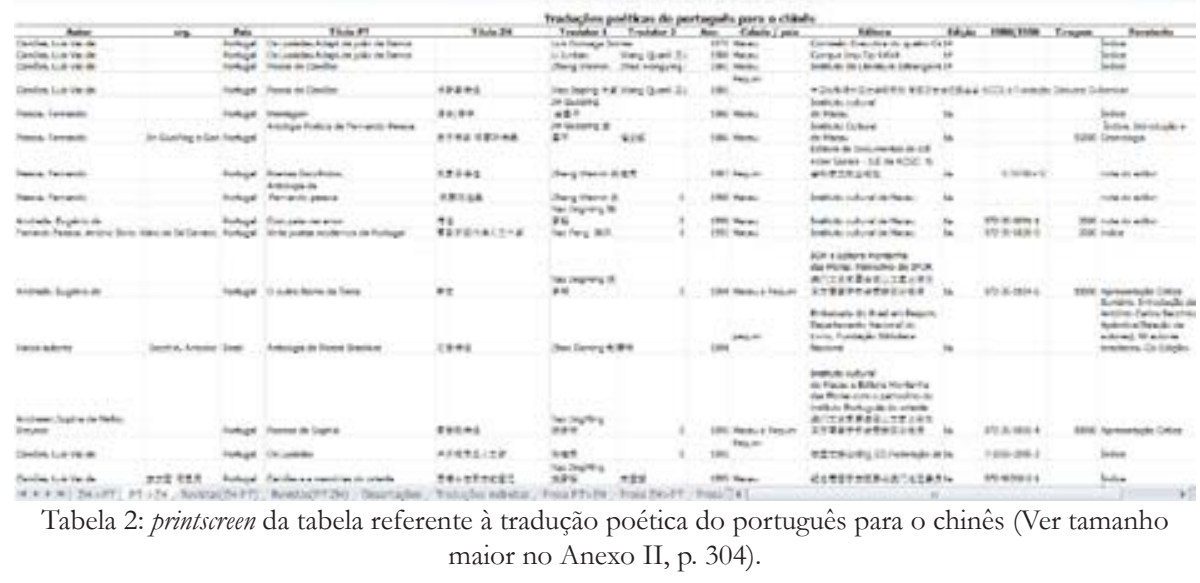

A montagem de um catálogo bibliográfico tem-nos provado, ao longo dessa pesquisa, que não se trata meramente de uma simples tarefa de coleta de dados (cf. tabelas 1 e 2 acima). Metaforicamente falando, as linhas verticais e horizontais de uma tabela, necessárias para os registros que nos propusemos a fazer, por vezes afiguram-se-nos como muros sólidos e compactos, que nos forçam a abrigar, mas também a repensar, conceitos também solidificados (embora frágeis e imprecisos), como por exemplo, o conceito de "tradutor(a) de poesia". Essa questão será ilustrada a partir de fichas catalográficas e de paratextos de livros de poesia traduzida 
analisados, de onde frequentemente se pode escutar a voz desses tradutores, e o modo como se autodefinem (ou mesmo como são definidos por outros agentes ou participantes do processo editorial dos livros traduzidos ou por outros agentes da indústria editorial) (vide também o artigo de HU, neste volume).

Desde as primeiras traduções de poemas chineses para o português, como os mencionados poemas traduzidos por António Feijó no livro Cancioneiro chinês (1890), que reuniu 17 poetas da dinastia Tang (618-907), questiona-se a atividade desse que é genericamente chamado de "tradutor de poesia". No mesmo ano de sua publicação, Luís de Magalhães, ao elogiar o trabalho de Feijó, no jornal $A$ Provincia, comenta o seguinte:

Recriando imaginativamente, mais do que traduzindo [grifo nosso], as versões em prosa de Le Livre de Jade, poésies traduites du chinois, título completo da antologia de Judith Gautier, António Feijó consegue dar expressão na sua forma portuguesa (justamente por ter adoptado um processo harmonioso de expansão das imagens poéticas) a duas das peculiaridades mais marcantes da poesia chinesa: a densidade semântica dos caracteres chineses e a sua inter-reflexidade em contexto poético, isto apesar de não ter contactado com as breves poesias originais. (MAGALHÃES, 1890 apud RAMOS, 2001)

A dificuldade de traduções diretas de poesia do chinês ao português continua a existir nos dias atuais. Ainda hoje, inúmeros poemas traduzidos entre os dois idiomas, principalmente do chinês ao português, resultam de tradução indireta, como comprovam os dados. Para Luís de Magalhães (1890 apud RAMOS 2011), Feijó "recria imaginativamente" as versões de Gautier. Tradução de tradução seria também tradução? recriação imaginativa? adaptação? invenção? Sempre que possível, informamos em nossa catalogação o(s) texto(s) tomado(s) como texto fonte pelo tradutor, mas nem sempre essas informações são apresentadas claramente nos livros. Em caso de grandes escritores que traduziram poesia chinesa, e com resultados belíssimos, como Machado de Assis e Cecília Meireles, é possível encontrar as traduções de onde partiram, apesar de comentários enxutos, como este de Cecília, na introdução de seu livro: "Estas traduções nem sempre concordam nas diferentes versões ocidentais confrontadas. Mas dão uma ideia, embora apagada, do gênio do velho poeta chinês Li Pó” (MEIRELES, 1996).

No livro da poetisa chinesa Shu Wang (2012), vertido para o português pela também poetisa portuguesa Fernanda Dias, os créditos de tradução constam do seguinte modo: "Versão portuguesa de Fernanda Dias. Tradução oral e literal por Stella Lee Shuk Yee". A experiência de tradução parece inédita e muito interessante. 
A partir da audição dos poemas, lidos em tradução literal por Stella Lee Shuk Yee, Fernanda Dias traduziu-os para o português. Certamente teve a chance de ouvi-los também em chinês para considerar sua musicalidade e efeitos sonoros no idioma fonte. Os poemas em português são belíssimos, o que não poderia resultar em algo diferente disso, se considerarmos a notável experiência e talento de Fernanda Dias na arte dos versos. No prefácio “Traduzir Shu Wang”, Fernanda escreve:

Seria imprudência da minha parte designar como tradução esta versão portuguesa de alguns poemas de Shu Wang; antes chamaria transmutação ou adaptação a esta tentativa de revelar na minha língua a atmosfera poética de parte da obra a que tive acesso. (DIAS, 2012, p. 8)

Não se trata de encontrar um equivalente exacto do poema original, antes uma revelação das imagens que devem sobreviver na passagem de uma língua para outra. (idem, p. 9)

Tradução como "transmutação", "adaptação", "versão poética", "reimaginação", "transcriação", "sobrevivência das imagens, na passagem de uma língua para outra", tradutor como inventor, como "tradutor-poeta" etc. Poderíamos listar um repertório de termos e diferenciações terminológicas da atividade desse que genericamente é denominado (por vezes forçosamente, como numa catalogação de poesia traduzida) como "tradutor(a) de poesia". Mas vamos finalizar aqui ressaltando um aspecto que tem se mostrado frequente nas traduções de poesia entre chinês e português, conforme os dados levantados: as duplas de tradutores. Muitas vezes um dos parceiros da tradução, por dominar o idioma de partida, cuida da tradução literal do poema, ao passo que o outro, com mais experiência literária e/ou poética na língua de chegada, finaliza a tradução poeticamente. Isso torna por vezes difícil nossa catalogação, pela própria autodefinição dos tradutores: um seria tradutor literal e outro seria recriador poético ou algo similar? Os dois seriam tradutores? Há inúmeras combinações de duplas, inclusive naturalmente duplas que conhecem muito bem os dois idiomas em questão. Para a primeira pergunta de D'hulst, portanto (Quis, quem), quem traduz, como se constata na prática, haveria grande diversidade de respostas possíveis e cabíveis numa ficha catalográfica, que no momento optamos por padronizar em nosso banco de dados com o termo genérico "tradutor(a)". Para o dicionário de tradutores, no entanto, as respostas a essa questão envolvem uma série de outros componentes, que dizem respeito não somente ao nível de conhecimento dos idiomas de partida ou de chegada de um tradutor, mas também a condicionantes sócio históricos, geográficos, políticos, ideológicos e culturais, entre outros que não poderiam deixar de ser verificados quando se trata de uma escrita historiográfica da tradução. 


\section{Referências}

D’HULST, Lieven. "Why and How to Write Translation Histories”. In: MILTON, John (org.). Crop, Vol. 6, Número especial: Emerging Views on Translation History in Brazil, 2001, pp. 21-32.

GASPAR, Lúcia; CUNHA, Lúcia Carvalheira. A presença chinesa no Brasil:pesquisa bibliográfica. Disponível em: http://api.ning.com/files/L8ju72LzRZ*GFScysFqrZCz8rGtXSfPB-9jJ sZrp*FgVdcuNDQzwTCoqsy0Pe37ot*66jNE7icVI9h*SSN0I0BxM-ESqudbx/Chineses_bibliografia_site.pdf. Acesso em: 23 de abril de 2013.

INSTITUTO PORTUGUÊS DO ORIENTE. Autores portugueses em linguas orientais. Macau: Instituto Português do Oriente, 2000.

KUHIWCZAC, Piotr; LITTAU, Karin. A Companion to Translation Studies. Topics in Translation 34. Clevedon: Multilingual Matters, 2007, pp. 1-12.

LIU, Yue Lian (Shu Wang). Poemas de Shu Wang [舒望詩集 Shū Wàng Shījí], tradução de Fernanda Dias e Stella Lee. Macau: Instituto Cultural de Macau, 2012.

MEIRELES, Cecília. Poemas chineses. Rio de Janeiro: Nova Fronteira, 1996.

MILTON, John; MARTINS, Marcia A. P. “Apresentação - Contribuições para Uma Historiografia da Tradução", in Tradução em Revista 1, 2010, pp. 01-10.

RAMOS, Manoela António Feijó e Camilo Pessanha no Panorama do Orientalismo Português. Lisboa: Fundação Oriente, 2001. Disponível em: http:/ / manueladlramoslivro2001.word press.com/, acessado em 29 de novembro de 2012.

SCHMALTZ, Márcia; ZHANG, Ye. "A tradução como instrumento de mudança: o tradutor Lu Xun”. Ouro Preto: Comunicação apresentada no X Encontro da Associação Brasileira de Tradutores, 2009.

SHEN, Yanbing [Mao Dun]. Baxi wenxuejia de yi ben xiaoshuo [Um romance de um literato brasileiro], in Xiaoshuō Yuekan, n. 2, 1921, pp. 4.

SHEN, Yanbing [Mao Dun]. Yinyan: weishenme yao yanjü bei sunhai de minzu wenxue [Apresentação: por que investigar a literatura dos povos oprimidos], in Xiaoshuo Yuekan, n. 10, 1921, pp. 2-7.

TENG, Wei. 'Biānjìng' zhì nán: Lādīng Měr z̧ōu wénxué hànyì yǔ Zhōngguó dāngdài wénxué: 1949-1999 [Ao sul da "Fronteira": A tradução da literatura latino-americana para o chinês e a literatura contemporânea chinesa: 1949-1999]. Pequim: Editora da Universidade de Pequim, 2011.

THE INTERNATIONAL HOUSE OF JAPAN LIBRARY. Modern Japanese Literature in Translation. A Bibliography. Tóquio, Nova Iorque, São Francisco: Kodansha, 1979.

THE JAPAN P.E.N. CLUB. Japanese Literature in Foreign Languages. 1945-1990. Tóquio: Japan Book Publisher Association, 1990.

YAO, Jingming. A poesia classica chinesa: uma leitura de traducões portuguesas. Macau: Universidade de Macau, 2001. 
ZHANG, Ye. A tradução literal como instrumento de mudança: o tradutor Lu Xun. Dissertação de Mestrado não-publicada. Macau: Universidade de Macau, 2009.

ZHOU, Shuren [Lu Xun]; ZHOU, Zuoren (1909/1973). Yuwai xiaoshuo ji [Romances além das fronteiras], in Lu Xun quanji [Obras completas de Lu Xun]. Xangai: Editora do Povo, Vol. 11, 1973. 